\title{
Terceirização de serviços públicos no Reino Unido e os impactos sobre as relações de trabalho: considerações sobre a realidade brasileira
}

\section{Apresentação}

A reestruturação da produção decorrente da crise do Fordismo trouxe, paripassu ao questionamento da presença do Estado na economia, o incremento nas politicas privatizantes, notadamente a partir de 1979, com a ascensão de governos (nco)liberais nos EUA e no Reino Unido (Lipietz, 1991).

A tendência privatizante no Reino Unido provocou o questionamento do papel do Estado, concretizando-se na venda de empresas estatais, incluindo os monopólios de prestação de serviços públicos (gás, eletricidade, petróleo e telecomunicações). 0 governo britânico foi mais além, incentivando experiências de privatização da prestação de serviços públicos municipais, como a limpeza de ruas, que passou a ser da responsabilidade de empresas privadas, num processo conhecido como terceirização.

No Brasil, a terceirização tem-se ampliado muito no âmbito das empresas estatais, abrangendo inclusive atividades-fim das empresas (como no caso das empresas operadoras dos serviços de telecomunicações). Os serviços de apoio, como portaria, recepção, segurança, cantina, faxina, digitação etc., já estão, de maneira geral, terceirizados nas empresas estatais. Serviços públicos municipais, como limpeza de ruas, já são terceirizados nas cidades brasileiras de grande porte.

Antonio Morcira de Carvalho Neto í engenheiro eletrònico e de telecomunicaçós pela PIC/MG : mestre em administraçāo pelo Centro de Pós-graduação e Pesquisas em Administração da Universidade Federal de Minas Gerais CEPEAD/MG 
O presente trabalho busca discutir a terceirização de serviços públicos no Reino Unido e traçar paralelos com a realidade brasileira.

A pesquisa no Reino Unido, feita em 1990, abrangeu o periodo de 1979 a 1990 e constou de entrevistas com dirigentes sindicais, gerentes responsáveis pela prestação de serviços públicos terceirizados nas prefeituras e/ou subprefeituras (como é o caso de Londres, que não tem uma prefeitura única) e gerentes das empresas privadas prestadoras dos serviços privatizados. Envolveu também análise documental e bibliográfica na Inglaterra. A pesquisa foi financiada pelo Conselho Britânico. No Brasil foram feitas entrevistas com dirigentes sindicais, pesquisa documental junto ao DIEESE e análise de jornais sindicais de 1979 a 1995.

\section{Reestruturação produtiva e precarização do mercado de trabalho}

O chamado sistema fordista de produção, vigente desde o pósguerra (1945) no Japão, Europa e EUA, basicamente, e que tinha como um dos seus pilares de sustentação a integração de grandes massas de trabalhadores an mercado de consumo, através de aumentos reais de salários, começou a dar sinais de crise monetária, social e de mercado a partir do final dos anos 60 (LIPIETZ, 1991).

Em 1971, os custos da Guerra do Vietnã e do papel de policial global, somados aos custos de manutenção do sistema econômico do pós-guerra (KURTZMAN, 1994) - que havia se tornado improdutivo, com desaceleração do crescimento da produtividade, crise do Welfare State c crise do modelo de consumo (Lipietz, 1991) - tinham exaurido a economia americana, além de terem transferido bilhões de dólares lastreados em ouro para o exterior (KunTZMan, 1994). Para responder à inflação, ao déficit na balança comercial e ao desemprego, em 15 de agosto de 1971 o presidente americano Richard Nixon desvinculou o valor do dólar da quantidade de ouro em reserva em Fort Knox, rompendo os acordos de Bretton Woods (1944), que haviam atrelado todas as moedas do mundo ao dólar (KURTZMan, 1994).

Essa crise do padrão monetário internacional (o dólar) instabilizou a economia mundial, na década de 70 , impondo ajustes macroeconômicos. Políticas antiinflacionárias recessivas foram adotadas nos paises envolvidos, com retração da demanda e do nivel de investimento e emprego (TaVAres, 1993). Além disso, a saturação de bens duráveis na Europa e EUA e o aumento da competitividade internacional das economias japonesa e curopéia (que se reconstruiram à sombra de um 
certo protecionismo, permitido pelos americanos devido à Guerra Fria) contribuíram para o agravamento da crisc (LIPIETZ, 1991).

A partir dos anos 70, devido à crise e às grandes dificuldades de essas economias se ajustarem aos choques externos (petróleo), a presença do Estado na cconomia, vista como benéfica na Europa do pós-guerra, passou a ser questionada. A concepção que defende o Estado liberal, retraido, que intervém apenas de maneira residual, somente regulando para resolver os conflitos c assegurar o funcionamento eficiente do mercado, freqüentemente intitulada "neoliberal", passou a se contrapor à concepção que defende o Estado Keynesiano, mais intervencionista, promotor e empreendedor do desenvolvimento cconômico e social (TAulle, ProcinniK et alii, 1994).

Os anos 80 trouxeram o boom das privatizações, com o advento dos governos liberais nos EUA c no Reino Unido, reforçados pela espetacular derrocada dos regimes do leste Europeu (KuRZ, 1992). A privatização c suas várias modalidades, com suas diferenças de intensidade, scja vendendo a maioria ou o total de ações do governo em uma empresa estatal, seja desregulamentando ou flexibilizando um setor de monopólio cstatal para permitir a concorrência com a iniciativa privada, scja contratando serviços de empresas particulares (terceirização, subcontratação), entrou em pauta definitivamente a partir dos anos 80 (S AVAS, 1987).

A privatização não vem isolada, no contexto de uma resposta à crise do Fordismo. As empresas multinacionais, nos setores de ponta da competição internacional, passam por uma recstruturação produtiva que reúne elementos de racionalização técnica c organizacional. A racionalização técnica tem substituído a mão-de-obra por agregados científicos com alto investimento de capital, como a mecatrônica (mudança da base metal-mecânica para eletrônica), com o concurso dos novos materiais (fibras óticas, por exemplo). A racionalização organizacional tem sido feita com o enxugamento drástico das estruturas cmpresariais fordistas, cujos processos produtivos têm sido redesenhados e a terccirização de serviços vem acompanhada de alta flexibilização do mercado de trabalho, com aumento dos part-time jobs e trabalhadores temporários. O processo de internacionalização da economia acelerou-se, pari passu a essa intensa recstruturação produtiva (LipIETZ, 1991; KURZ, 1992).

A globalização da economia c o acirramento da competição internacional forçam a busca de novos mercados, que leva à forte intensificação nas pressões para quebra de barreiras comerciais, o que implica cm privatização e desregulamentação ou flexibilização. As estratégias realmente globais envolvem vendas mundiais, buscando componentes e materiais de baixo custo por todo o mundo (PORTER, 1993).

A reestruturação produtiva em curso, com sua tendência à redução de estoques, dos tempos de projeto e fabricação e de investimentos (uni- 
dades de produção menores), à desregulamentação de direitos trabalhistas, à flexibilização das normas de trabalho e à ideologia da competitividade, aliada à substituição da mão-de-obra e à racionalização organizacional, veio agravar ainda mais a crise social no âmbito do G-7 (LIPIETZ, 1991).

Essa situação tem induzido a uma forte polarização social nas socicdades mais desenvolvidas da Europa e Estados Unidos, um fenômeno que LIPIETz chama de "abrasileiramento" (p. 61).

Mesmo o Japão teve sua decantada estabilidade social atingida, principalmente a partir da drástica desvalorização do dólar americano frente ao iene, no inicio do atual governo dos EUA, o que ocasionou um aumento dos custos de produção japoneses e promoveu a transferência de unidades de produção para fora do Japão. O emprego vitalício está desaparecendo no Japão, a transferência de trabalhadores para niveis inferiores em empresas parceiras está aumentando c têm ocorrido muitas demissões (OsAwa, in: Hirata, 1993).

O descmprego estrutural tornou-se um problema permanente nos paises desenvolvidos e um problema endêmico nos paises periféricos. (KuRz, 1992). Basta observarmos as altas taxas de desemprego em 1993, apontadas pela OIT (1994): $11,2 \%$ no Canadá; $6,9 \%$ nos EUA; $2,5 \%$ no Japão; $8,9 \%$ na Alemanha; $11,7 \%$ na França; $10,2 \%$ na Itália; $10,3 \%$ no Reino Unido; $8,2 \%$ na Sućcia; $22,7 \%$ na Espanha e $12,1 \%$ tanto na Bélgica quanto na Dinamarca.

Como conseqüência deste quadro de desemprego estrutural, aliado às políticas de privatização que atingiram o Estado de Bem-Estar Social e à reestruturação produtiva, podemos ver um númcro cada vez maior de trabalhadores divididos entre empregos precários ou desempregados c um grupo cada vez menor e progressivamente desestabilizado de trabalhadores semiqualificados, em contraposição ao minúsculo clube dos vencedores, dos escolhidos, dos superqualificados (LipIETZ, 1991; KuRZ, 1992).

A visão espantosamente ingênua de uma ordem econômica mundial próspera e harmoniosa, baseada no laissez-faire, mostra uma incapacidade de reconhecer que as mais novas tecnologias $\mathrm{e}$ as modificações profundas na produção econômica e nas comunicações podem, segundo KenNedY (1993), trazer também desvantagens.

\section{Diferentes faces das políticas de privatização}

Freqücntemente o termo privatização é usado como uma espécic de guarda-chuva, que engloba as politicas de contratação temporária de mão-de-obra, terceirização, desregulamentação e privatização de fato. 
A seguir, são apontadas as políticas mais freqüentemente implantadas, tanto pelas empresas estatais quanto por órgãos públicos municipais, estaduais e federais.

\section{1. Terceirização}

É a prestação de serviços, no nosso caso serviços de apoio nos órgãos públicos, contratada de firmas particulares. Numerosos órgãos governamentais (serviço público) têm contratado prestadores de serviços privados no Reino Unido, principalmente nas áreas de coleta de lixo urbano, alimentação/refeitórios, limpeza, construção e manutenção de prédios e obras públicas.

\section{2. Desregulamentação}

É a retirada das restrições à entrada de empresas privadas para competir no mercado antes reservado às empresas públicas, em regime de monopólio. Pode tomar a forma de encorajar empresas estatais e/ou privadas a competirem umas com as outras.

\section{3. Privatização}

É a venda das cmpresas estatais na Bolsa de Valores ou diretamente à iniciativa privada. $O$ Estado passa de acionista majoritário a minoritário, ou vende todas as suas ações. Nos processos de venda de ações de empresas estatais a empresas privadas ou a pessoas fisicas na Grã-Bretanha, houve casos em que o governo fixou uma quantidade máxima de ações que cada comprador, bem como as pessoas fisicas, poderia ter de início. Houve casos em que vendeu diretamente a empresas, sem a entrada de pessoas fisicas no negócio.

\section{A terceirização dos serviços públicos no Reino Unido}

A partir de 1979, com a ascensão da corrente neolibcral ao governo britânico, os municipios e órgãos públicos centrais foram incentivados a contratar serviços de firmas privadas.

Essa política refletia uma visão de que o Estado precisava se retirar inclusive da exccução de funções consideradas até então públicas por excelência, como a manutenção c limpeza de vias públicas, passando a assumir um caráter regulador na prestação desses serviços pela iniciativa privada. 
Na Grã-Bretanha, os serviços de coleta de lixo urbano, limpeza de ruas, limpeza e manutenção de hospitais e manutenção de prédios públicos passaram a ser contratados de firmas privadas.

\subsection{Impactos da terceirização sobre o} trabalho, os custos e a qualidade dos serviços

Para o Labour Research Department(1987), dirigentes sindicais e gerentes responsáveis pelos serviços públicos entrevistados, a terceirização dos serviços públicos significou:

a) Demissão de servidores públicos:

- $37,2 \%$ do pessoal empregado na coleta de lixo e limpeza de ruas foi demitido;

- $20 \%$ do pessoal empregado na limpeza e manutenção de hospitais foi demitido;

- $3 / 4$ dos demitidos cram mulheres, porque a grande maioria de contratações vinha sendo feita na área serviços/limpeza. É interessante notar que, como indica este dado, as mulheres, mesmo nos paises de capitalismo avançado, continuam sendo maioria nas tarefas menos reconhecidas socialmente, cujos salários são menos atraentes.

b) Salários:

- invariavelmente a terceirização significou rebaixamento nos salários $(25 \% \mathrm{em}$ média de queda nos niveis salariais dos trabalhadores).

- Em alguns casos, os trabalhadores não recebiam aumentos salariais, como os trabalhadores na limpeza das ruas da localidade de Wandsworth de 1982/86;

- os salários dos trabalhadores de limpeza que são organizados $\mathrm{cm}$ sindicatos são $15 \%$ mais altos do que os salários daqueles que não o são.

- Houve greves seguidas de negociações e algumas conquistas salariais de movimentos reivindicatórios, mas as evidências são de que a tarefa de organizar os trabalhadores e assegurar condições de emprego e salário, ao menos iguais às que tinham os funcionários públicos, é dificílima quando se trata de pessoal terceirizado, geralmente pulverizado por várias empresas diferentes e submetidos a alta rotatividade.

c) Condições de trabalho:

104 - nenhuma proteção contra doença, demissão c aposentadoria; 
- enquanto as prefeituras concedem 39 horas semanais, férias de 20 dias no primeiro ano de trabalho, licença médica de 26 semanas com pagamento total e pensão de aposentadoria para trabalhadores da coleta de lixo, as empresas privadas contratadas pelas prefeituras oferecem $40 \mathrm{~h}$ semanais, férias de 6 a 15 dias no primeiro ano, licença médica de quatro semanas com pagamento total e negam pensão para aposentadoria; - as trabalhadoras na limpeza e as domćsticas foram as que sofreram a maior deterioração nas condições de trabalho, pois muito poucas trabalham mais de 16 horas semanais, como resultado do corte de horas de trabalho. Isso significou não só uma perda de ganhos, mas também uma perda nos direitos de reclamar na justiça por demissão sem justa causa, beneficios extras, ajuda-maternidade, tempo disponivel para atividades sindicais ou pagamento por afastamento temporário, direitos estes baseados em um mínimo de horas de trabalho. Virtualmente, nenhuma delas é paga semanalmente o suficiente para habilitá-las a receber auxílio-doença, pensões, salário-desemprego e outros beneficios que dependam do montante da contribuição. Quando sair para férias, a trabalhadora deve apresentar outra para substituí-la (geralmente não têm direito a férias no primeiro ano por trabalharem poucas horas e só têm direito a 10 dias no segundo ano contra 20 dias do serviço público). A rotatividade é alta, aparentemente devido às condições de salário e trabalho.

d) Custos:

Segundo Vickers e Yarrow (1988), os servidores públicos, que antes se beneficiavam de uma posição de monopólio, foram colocados frente a frente com a competição do setor privado, e a evidência dos números e dados mostra importantes ganhos em custos.

Já para o LABOur Research DePARTMEnt (1987), a queda no nível de emprego, resultante da terceirização de serviços públicos, significa aumento em outros beneficios que são pagos pelo governo, como salário-dcsemprego, alćm de fazer crescer a demanda por serviços sociais (reduções em transporte, lazer e serviços médicos a que o desempregado tem direito. Por exemplo: uma economia imediata de 1,3 milhões de libras esterlinas resultante de corte em empregos públicos, devido à terceirização de serviços, significa 2,0 milhões de libras a mais de gastos públicos $\mathrm{em}$ cinco anos.

c) Qualidade dos serviços:

Há dificuldades no gerenciamento das empresas contratadas: tanto VICKERS C YARROW (1988) quanto o LABOUR (1987) concordam que o 
gerenciamento ou monitoramento das empresas contratadas é dificil. Segundo Vickers e YARROW (1988), a terceirização traz dificuldades de especificações e monitoramento: se há uma incerteza devido à reação do mercado ou problemas tecnológicos em relação a um produto ou serviço a ser oferecido, então a especificação do contrato de concessão pode ser uma tarefa muito complexa c uma continuada relação contratual é neccssária, o que envolve custos adicionais permanentes (os contratos acabam ficando 10 a $15 \%$ mais caros do que o que foi inicialmente contratado). Em vários casos, a alternativa é a concessionária ficar à mercê da firma contratada.

A autoridade pública recusa-se, $\mathrm{cm}$ vários casos (por exemplo, o Morthwick Park Hospital) a accitar a responsabilidade quando há queixas sobre a qualidade dos serviços e, simplesmente, passa as queixas para a firma contratada.

A ruptura de um contrato pelo fato de a empresa privada contratada não estar cumprindo as obrigações mínimas cria dificuldades adicionais para o Serviço de Saúde providenciar imediata substituição da contratada e continuidade dos serviços.

Em contratos de limpeza, as autoridades têm repetidamente encontrado dificuldades para impor melhorias no desempenho (LABOUR, 1987).

\section{2. A terceirização no Reino Unido estimulou a concorrência?}

Segundo Vickers e Yarrow (1988), a terceirização nem sempre estimula a competitividade entre empresas, pois a experiência ganha durante o contrato habilita a empresa que ganhou a concorrência para prestar o serviço a reduzir seus custos de operação num primeiro período. Assim, a concessão para o próximo período é ganha geralmente pela firma que já está prestando o serviço, mais do que qualquer outra que queira disputar com ela.

Uma séric de compras e fusões de companhias prestadoras de serviços eliminou progressivamente quase toda competição, estabelecendo o domínio do mercado por duas firmas de limpeza, as multinacionais BET (maioria de capital inglês) e Hawley Group (maioria do capital dos U.S.A), ambas operando também na África do Sul. A BET e o grupo Hawley detêm $62 \%$ de todos os contratos feitos por prefeituras para coleta de lixo e limpeza de ruas, $46 \%$ dos serviços de prédios públicos e $53 \%$ dos serviços de limpeza nos hospitais públicos. Podemos observar, portanto, um "duopólio" estabclecido e que não tem concorrido entre si. 
O LABOUR (1987) atesta que na Grã-Bretanha todas as firmas prestadoras de serviço têm sido persistentes lobistas políticos, pressionando o governo para estender o leque de áreas onde se passaria a permitir a contratação; este lobby é baseado $\mathrm{cm}$ ligações fortes através de doações de fundos aos partidos politicos ou de frentes de levantamento de fundos para partidos (como a organização chamada "Industriais Britânicos Unidos"), além da presença de parlamentares c lordes (cargo herdado da familia pertencente à nobreza britânica) como consultores pagos ou diretores das firmas prestadoras de serviços (por exemplo, a BET doou 25.000,00 libras esterlinas para o Partido Conservador $\mathrm{cm}$ 1985/6; R.H.Christopher Chataway, que foi ministro de governo e deputado pelo Partido Conservador, é diretor da BET).

\section{Reflexões sobre a realidade brasileira e paralelos com o Reino Unido}

A terceirização, também chamada de focalização, é, como dito anteriormente, uma tendência internacional, destinada à redução de custos fixos e à concentração de esforços no negócio especifico da empresa, abandonando sistemas produtivos mais complexos e menos flexiveis, como as estruturas fordistas.

Associada às novas técnicas organizacionais, a terceirização é mais generalizada nos setores de ponta da economia. Não é por acaso que essa tendência vem se acentuando no Brasil, na região do $A B C D$ paulista. Terceirização vem, geralmente, associada a enxugamento de estruturas organizacionais, com as conseqüentes demissões; a perdas de beneficios e vantagens salariais constantes dos acordos coletivos sindicais; à precarização dos vinculos empregatícios e ao crescimento do trabalho temporário (DIEESE, 1994).

Relatos dos dirigentes sindicais entrevistados' e pesquisa do DIEESE (1994) indicam maior dificuldade de organização sindical com a pulverização dos trabalhadores entre várias empresas.

Antes estes trabalhadores pertenciam a um único sindicato $\mathrm{e} a$ uma única empresa e tinham, portanto, maior poder de organização sindical, mais conquistas salariais e de beneficios (plano de saúde, valetransporte etc.), invariavelmente perdidos ou rebaixados com a demissão da empresa de origem e contratação por uma empresa prestadora de serviços. Há salários que apresentam queda de $50 \%$ ou até mais.

Esse quadro contribui para a expansão do setor informal da economia. A informalização da economia já atinge por volta de metade da população economicamente ativa no Brasil, e tenderá a aumentar no 
tempo, para absorver os excedentes oriundos da agricultura e da cconomia competitiva (Drmo, 1994).

A terceirização ocorre no Brasil $\mathrm{cm}$ alto grau $\mathrm{cm}$ setores importantes da economia, como os setores bancário, metalúrgico, petroleiro, petroquimico e de telecomunicações. Ocorre no mesmo grau, independentemente do regime de propriedade da empresa, se pública ou privada.

A terceirização "à brasileira" se dá basicamente por dentro da empresa contratante, prioritariamente nas áreas de apoio (limpeza, alimentação, segurança etc.), como indica levantamento da Coopers \& Librand, em 87 grandes empresas brasileiras, cm outubro de 1994.

Há a terceirização feita através de empreiteiras privadas, que prestam serviços dentro da empresa contratante, muitas vezes os mesmos serviços que são também prestados por trabalhadores efetivos da empresa contratante. Há casos de empresas nas quais o número de trabalhadores em empreiteiras $\mathrm{c}$ outras firmas prestadoras de serviços no interior da mesma chega a ultrapassar o número de trabalhadores da contratante.

No Brasil, ainda não há estatísticas e dados confiáveis, no tocante à terceirização de serviços públicos anteriormente prestados por prefeituras e órgãos estaduais. Como foi dito anteriormente, os serviços de apoio prestados pela maioria dos referidos órgãos são terceirizados, bem como a limpeza de rua e coleta de lixo $\mathrm{cm}$ cidades de grande porte, onde é mais comum a convivência entre serviços prestados diretamente pela prefeitura $\mathrm{e}$ terceirizados.

A ausência de dados referentes às prefeituras $\mathrm{e}$ órgãos estaduais é, em parte, explicada pela inexistência de ação sindical organizada no setor público até a promulgação da Constituição de 1988, sendo que até então cra proibida a sindicalização do funcionalismo público. Com exceção do professorado, as demais categorias do funcionalismo começaram a se organizar a partir do fim da proibição.

Devido a cssa limitação, a pesquisa foi feita no setor público estatal, em muitos casos, nas empresas estatais de eletricidade, petróleo e telecomunicação, que permite comparação e no qual há sindicatos organizados desde os anos 60 . Nestas empresas, o processo de terceirização ocorreu não só nos setores de apoio, como faxina, cantina ctc., mas também como estratégia para contornar a proibição governamental de contratação de pessoal, que vigorou durante toda a década de 80. Devido à necessidade de implementar e operar novas redes de energia e telecomunicações, além das novas plantas petroliferas, o número de empreiteiras que passou a operar dentro das empresas estatais contratantes aumentou expressivamente. 
A partir de levantamentos feitos pelo DIEESE e de pesquisa junto aos sindicatos de petroleiros, telefônicos e eletricitários de Minas Gerais, no período de 1979 a 1995, é possivel concluir que:

- os salários de funções equivalentes são sensivelmente menores na empresa contratada (por exemplo, um trabalhador em telecomunicações cuja função ć de emendador de cabos ganha menos da metade ao exercer a mesma função cm uma empreitcira);

- as condições de trabalho, nas empresas contratadas, são geralmente bastante inferiores, bem como o sistema de concessão de beneficios;

- nas firmas maiores e mais organizadas, especialmente nas prestadoras de serviços técnicos, há um mínimo de cumprimento de obrigações trabalhistas, como direito a férias, $13^{\circ}$ salário, carteira assinada, pagamento dc FGTS c ao INSS, cmbora sejam raros os beneficios que não estejam claramente estabclecidos na legislação;

- nas firmas prestadoras de serviços de apoio, salvo raras exceçõcs, a situação é ainda mais deteriorada, no tocante às condições de trabalho, apresentando, alcm disso, alto grau de precariedade do contrato de trabalho (não são raros os casos $\mathrm{cm}$ que sequer os depósitos do FGTS e INSS são feitos, com o conseqüente fechamento da empresa prestadora de serviços e o providencial desaparecimento do micro-empresário...);

- o nivel de emprego cai cm todas as situações, devido ao saldo ncgativo entre a destruição de postos de trabalho na contratante c a criação de novos postos na contratada;

- a intervenção sindical organizada ć dificultada pela pulverização dos trabalhadores entre diferentes empresas e bases sindicais;

O quadro acima permite traçar paralelos com os efeitos da terceirização de serviços públicos sobre as relações de trabalho no Reino Unido. A queda no nivel de emprego, nos salários, nas condições de trabalho c a precarização dos contratos de trabalho está presente nas duas realidades.

A discussão sobre a redução de custos permanece polêmica, tanto no Reino Unido quanto no Brasil, onde os argumentos são semelhantes. Denúncias de corrupção, que afetariam os custos, não são raras nos dois casos, sempre levantadas pelos sindicatos dos dois paises que encontram, na presença de cx-diretores c ex-funcionários graduados da contratante na direção das prestadoras contratadas, indices de favorecimento c cartelização. Mesmo no caso da iniciativa privada, há esse tipo de denúncia (DIEESE, 1994). 


\section{Considerações finais}

Os efeitos da terceirização de serviços públicos nas relações de trabalho apresentam as mesmas caracteristicas da iniciativa privada.

No bojo da reestruturação produtiva, a terceirização contribui para aumentar o desemprego, para a precarização dos contratos e das condições de trabalho, influindo positivamente - em conjunto ou como parte de outras novas tecnologias organizacionais que expressam a atual tendência internacional à flexibilização do mercado de trabalho - para a maior informalização da cconomia deste fim de sćculo.

Segundo Mattoso (1994), é amplamente reconhecido que os trabalhadores, cujos contratos de trabalho foram flexibilizados dentro da OCDE, tiveram salários rebaixados e o acesso à seguridade social e assistência médica restringido ou eliminado.

Em 1991, 40\% do emprego na Inglaterra já era constituido pela mão-de-obra contratada temporariamente, na sua maioria excluida do sistema de impostos e beneficios sociais (MatToso, 1994), como resultado de politicas privatizantes (entre as quais se insere a terceirização) e de flexibilização do mercado de trabalho, trazidas pelas novas técnicas organizacionais. Podemos imaginar a dimensão social dos impactos que estes processos estão trazendo ao mercado de trabalho brasileiro, cujo perfil já é de acentuada hetcrogencidade.

Os sindicatos de trabalhadores, num quadro destes, têm sua ação extremamente dificultada, ainda mais num pais com uma clevada concentração de renda e alto grau de informalização da economia como o Brasil. O acordo da Comissão de Fábrica da Volksvagen em São Bernardo do Campo (SP), garantindo negociação da empresa com o sindicato no caso de terceirização, é bastante raro e relevante.

Esse pode ser um caminho para que a terceirização se dê dentro de um espirito de efetiva modernização industrial, como parte de alternativas concretas e mais abrangentes $\mathrm{cm}$ termos de política industrial (DIEESE, 1994).

Nota

' Corroborados por pesquisas feitas $\mathrm{cm}$ jornais, boletins e revistas periódicas dos sindicatos dos trabalhadores em telecomunicaçðes, eletricitários e petroleiros de Minas Gerais, de 1979 a 1995. 


\section{Bibliografia}

Demo, Pedro. O futuro do trabalhador do futuro. Brasilia: OIT, 1994.

DIEESE. Trabalho e Reestruturação Produtiva. São Paulo: Parma, 1994.

Hirata, H. (org.) Sobre o modelo japonès. São Paulo: Edusp, 1993.

Kennedy, Paul. Preparando para o Século XXI. Rio de Janeiro: Campus, 1993.

Kurz, Robert. O Colapso da Modemização. Rio de Janeiro: Paz e Terra, 1992.

Kurtzman, Joel. A Morte do Dinheiro: como a economia eletronica desestabilizou os mercados mundiais e criou o caos financeiro. São Paulo: Atlas, 1994.

Labour Research Department. Privatisation - paying the price. Londres, 1987.

I.jPietZ, Alain. Audácia: uma altemativa para o século XXI. São Paulo: Nobel, 1991.

Mattoso, Jorge. "O novo e inseguro mundo do trabalho nos paises avançados".

In: $O$ mundo do trabalho. Projeto MTb / PNUD. Campinas, páginas abertas, 1994.

ОІт. "El trabajo en el mundo: la situación mundial del empleo". Genebra, 1994.

PorTer, Michacl E. A Vantagem Competitiva das Naçðes. Rio de Janeiro: Campus, 1993.

Savas, E. S. Privatização: a chave para um governo melhor. Rio de Janeiro: Nordica, 1990.

TAuile, J. R., Prochnik, V. et alii. "Telecomunicaçōes: mudança tecnológica e suas implicaçð̃es económicas, sociais e institucionais". Rio de Janeiro: Instituto de Economia Industrial da UFRJ, Convênio EMBRATEL, Relatório Final, 1994.

Vickers, J. E Yarrow, G. Privatization - an economic analysis. Cambridge, Mass: MIT Press, 1988.

\section{Resumo}

Resumen

Abstract

Terceirização de serviços públicos no Reino Unido e os impactos sobre as relações de trabalho: consideraçōes sobre a realidade brasileira

Antonio Moreira de Carvalho Neto

A partir da crise do Fordismo, a reestruturação produtiva globalizou-se, nos paises mais desenvolvidos, impulsionada pelo aumento da competição internacional. Isto reforçou a concepção que defende o Estado (neo) liberal, intervindo na economia somente para regular os conflitos de mercado, em contraposição ao Estado Keynesiano. Esta reestruturação reúne elementos de racionalização organizacional, que trazem políticas de mudanças nas relaçðes de trabalho ocasionadas, entre outros fatores, pela contrataçăo de mão-de-obra temporária e pela terceirização. O presente trabalho, baseado em pesquisa realizada na Inglaterra, analisa os impactos da terceirização sobre as relaçoes de trabalho, discutindo os paralelos com a realidade brasileira. 
Externalización* de los servicios públicos en el Reino Unido y los impactos sobre las relaciones de trabajo: consideraciones sobre la realidad brasileña.

Antonio Moreira de Carvalho Neto

A partir de la crisis del Fordismo, la reestructuración productiva se ha globalizado en los paises desarrollados, impulsada por el aumento de la competitividad internacional. Ello ha reforzado la concepción que defiende el Estado (neo) liberal, interviniendo en la economía solamente para regular los conflictos de mercado, en contraposición al Estado Keynesiano. Esta reestructuración reune elementos de racionalización organizacional, que traen políticas de cambio en las relaciones de trabajo ocasionadas, entre otros factores, por la contratación de mano de obra temporaria y por la externalización. El presente trabajo, basado en investigación realizada en Inglaterra, analiza los impactos de la externalización sobre las relaciones de trabajo, discutiendo los paralelos con la realidad brasilena.

- En Brasil, se denomina Terceirização.

Use of third-party Public Service contractors in the United Kingdom and its impact on labour relationships: sume notes on the Brazilian reality

Antonio Moreira de Carvalho Neto

As from the crisis of Fordism, the productive restructuring has become global in more developed countries, stimulated by the increase in international competition. This has reinforced the idea sponsored by the (neo)liberal State, of intervening in the economy only to regulate market conflicts, as opposed to the Keynesian State. This restructuring combines elements of organisational rationalisation, which bring about policies of change in the labour relationships, which are caused, imter alia, by the hiring of temporary manpower and the use of third-party contractors. This article, based upon research conducted in the United Kingdom, analyses the impact of the use of third-party contractors on labour relationships, and discusses its paralIels with the Brazilian reality. 